\title{
ANALISIS MAKNA BHINEKA TUNGGAL IKA DALAM IKLAN EDISI “BU LINDA” PADA YOUTUBE CHANEL BUKALAPAK
}

\author{
Muhammad Rusdi Tanjung \\ Desain Komunikasi Visual \\ Fakultas Seni dan Desain Universitas Potensi Utama \\ rsd.adi@gmail.com
}

\begin{abstract}
ABSTRAK
Iklan selalu memiliki pesan tersembunyi dalam penyampaiannya. Bukalapak adalah web commerce yang berkembang pesat di Indonesia saat ini. Penelitian ini mengambil iklan yang tayang pada youtube chanel Bukalapak edisi "bu Linda" yang dipublikasi pada 26 Januari 2017, iklan ini bertemakan perayaan Imlek. Penelitian ini bertujuan untuk mendeskripsikan makna Bhineka Tunggal Ika yang terkandung didalam iklan tersebut. Metode penelitian yang digunakan adalah deskriptif analitik dengan menggunakan teori semiotika Roland Barthes. Penelitian fokus pada adegan-adegan didalam iklan yang merepresentasikan makna kebhinekaan. Iklan ini menjadi menarik dianalisis karena menggambarkan tali persaudaraan tidak harus dari kesamaan keyakinan, tetapi dapat dari perbedaan keyakinan, baik suku, agama, dan etnis/ras. Hasil dari analisis iklan pada youtube channel Bukalapak edisi "bu Linda" ini ditemukan beberapa pemaknaan sebagai berikut : (1) Pertalian Antara Ibu Dan Anak, (2) Sahabat Adalah Saudara, (3) Perbedaan Keyakinan Tetap Bersaudara.
\end{abstract}

Kata Kunci: semiotika komunikasi, makna Kebhinekaan, iklan

\section{ABSTRACT}

Ads always have hidden messages in their delivery. Bukalapak is a fast growing web commerce in Indonesia today. This study took an ad that aired on the youtube channel Bukalapak edition "bu Linda" published on January 26, 2017, this ad was themed Chinese New Year celebration. This study aims to describe the meaning of Bhineka Tunggal Ika contained in the advertisement. The research method used is descriptive analytic using Roland Barthes's semiotic theory. Research focuses on scenes in the ad that represent the meaning of diversity. This advertisement becomes interesting because it describes the brotherhood does not have to be from the same belief, but can be from differences in beliefs, both ethnicity, religion, and ethnicity / race. The results of the analysis of the ad on the Bukalapak edition of the channel "Bu Linda" found a number of meanings as follows: (1) Relationship Between Mother and Child, (2) Friends Are You, (3) Differences in Belief in Permanent Brothers.

Keywords : communication semiotics, the meaning of diversity, advertising 


\section{PENDAHULUAN}

\section{Latar Belakang}

Media sekarang ini menjadi suatu saluran yang penting bagi masyarakat luas, karena fungsi dan manfaatnya telah menyatu dalam kehidupan sehari-hari, yang dihasilkan oleh pesatnya perkembangan teknologi.

Iklan sebagai media yang sangat dekat dengan kehidupan masyarakat sekarang ini dan menjadi budaya modern yang dengan mudah ditemui dimana saja dan kapan saja, melalui iklan produsen akan menyampaikan pesan atas keunggulan-keunggulan produknya kepada konsumen. Namun dalam penyampaiannya iklan selalu memiliki makna tersembunyi.

Iklan didefinisikan sebagai pesan yang menawarakan suatu produk yang ditujukan kepada masyarakat lewat suatu media yang sekaligus bertujuan mempersuasi orang untuk membeli (frank.F, 1982:111). Setiap pesan dalam iklan memiliki dua tingkat makna, yakni makna yang dikemukakan secara eksplisit dipermukaan makna dan makna implicit dibalik permukaan tampilan makna (Novianti, 2002:79). Iklan adalah suatu bentuk komunikasi massa komersial yang dirancang untuk mempromosikan pemasaran suatu produk atau jasa, maupun pesan dari suatu lembaga, organisasi, bahkan bisa juga pesan dari seseorang yang mengkampanyekan tentang sesuatu. (Wahyuningsih, 2013:129).

Semiotik sebagai ilmu yang digunakan untuk menginterpretasi pesan (tanda) yang dipertukarkan dalam proses komunikasi. Dengan menggunakan teori semiotika, kita dapat menganalisa berbagai tanda dalam iklan yang disebarkan melalui media cetak, televisi, maupun media online (internet). Media dalam penyebarannya memiliki peranan yang sangat penting sebagai sumber penyampaian gagasan tentang budaya populer karena budaya popular membutuhkan media sebagai sarana mendistribusikan ide.

Semiosis adalah proses pembentukan tanda yang bertolak dari representamen yang secara spontan berkaitan dengan object dalam kognisi manusia dan kemudian diberi penafsiran tertentu oleh manusia yang bersangkutan sebagai interpretant. (Hoedoro, 2014:9). Sebuah iklan selalu berisikan unsur-unsur tanda berupa objek (object) yang diiklankan; konteks (context) berupa lingkungan, orang atau makhluk lainnya yang memberikan makna pada objek; serta teks (berupa tulisan) yang memperkuat makna (anchoring). (Yasraf, 2003:263).

Berdasarkan latar belakang yang telah dijelaskan tersebut penulis melakukan penelitian dengan menganalisis makna Bhineka Tunggal Ika yang dihasilkan pada iklan yang ditayangkan melalui chanel online youtube milik Bukalapak edisi "Bu Linda" yang di publikasi pada 26 Januari 2017.

Iklan tersebut menceritakan dua orang anak muda bernama Ari dari Jawa dan Mario dari kota Ambon, yang menjalani studi di salah satu perguruan tinggi dikota Bandung, mereka tinggal dengan menyewa kamar dirumah seorang wanita paruh baya yang hidup sendiri.

Dari situ terciptalah kehidupan keseharian dan terjalinnya rasa kekeluargaan antara ibu dan anak yang dilandasi dengan perbedaan suku, agama dan ras yang dapat saling berdampingan antara penghuni kamar sewa dengan pemilik rumah. Hingga kedua anak muda penghuni kamar sewa tersebut menyelesaikan studi, dan setelah 10 tahun kemudian ke-dua anaknya berkumpul kembali dalam keadaan sudah mapan dan membawa keluarga masing-masing untuk merayakan tahun baru Imlek bersama-sama.

\section{Metode Penelitian}

Dalam penelitian ini penulis menggunakan metode penelitian kualitatif dengan jenis penelitian bersifat deskriptif analitik. Penelitian deskriptif adalah studi untuk menemukan 
fakta dengan intepretasi yang tepat, sedangkan analisis ditujukan untuk menguji hipotesishipotesis dan mengadakan intepretasi yang lebih dalam tentang hubungan-hubungan (Nazir, 2005:89).

Penelitian deskriptif analitik adalah penelitian yang dilakukan untuk menggambarkan, menguraikan dan menjelaskan objek penelitian untuk kemudian dilakukan studi kritis terhadapnya (Arikunto, 1998: 245).

Penelitian kualitatif adalah sebuah prosedur penelitian yang menghasilkan data deskriptif berupa tulisan, ucapan, maupun prilaku dari objek yang diteliti (Bogdan dan Taylor, 1992: 21).

Tahap awal yang dilakukan dengan menyaksikan dan memahami keseluruhan isi iklan dari youtube chanel Bukalapak edisi "Bu Linda" yang berdurasi 6 menit 27 detik, kemudian dilakukan penyeleksian berdasarkan adegan-adegan yang merepresentasikan wujud dan sikap dari kata "Bhineka Tunggal Ika". Penelitian ini berusaha untuk menemukan makna dari tanda-tanda yang tersembunyi dan pesan yang terkandung didalam iklan ini.

Setelah proses analisis makna dilakukan, penulis mengambil kesimpulan atas hasil penelitian yang dilakukan.

\section{Landasan Teori}

Teori yang digunakan pada penelitian ini adalah teori semiotika Roland Barthes yang mengacu pada pemahaman bahasa tanda adalah peran dari pembaca (reader) agar dapat berfungsi. Dalam semiologi Roland Barthes mengulas pemaknaan secara konotasi dan denotasi.

Barthes (dalam Sobur, 2009:70) menjelaskan bahwa denotasi merupakan system signifikasi tingkat pertama, sedangkan konotasi merupakan tingkat kedua. Denotasi lebih diasosiasikan dengan ketertutupan makna dan, dengan demikian, sensor atau represi politis.

Dalam kerangka Barthes, konotasi identik dengan operasi ideologi, yang disebutnya sebagai "mitos", dan berfungsi untuk mengungkapkan dan memberikan pembenaran bagi nilai-nilai dominan yang berlaku dalam satu periode tertentu. (Budiman, 2001:28)

Mengacu pada Hjelmslev, Barthes (1983) sependapat bahwa bahasa dapat dipilih menjadi dua sudut artikulasi. (dalam Kurniawan, 2001:67) sudut artikulasi menurut Barthes digambarkan dalam bentuk seperti berikut:
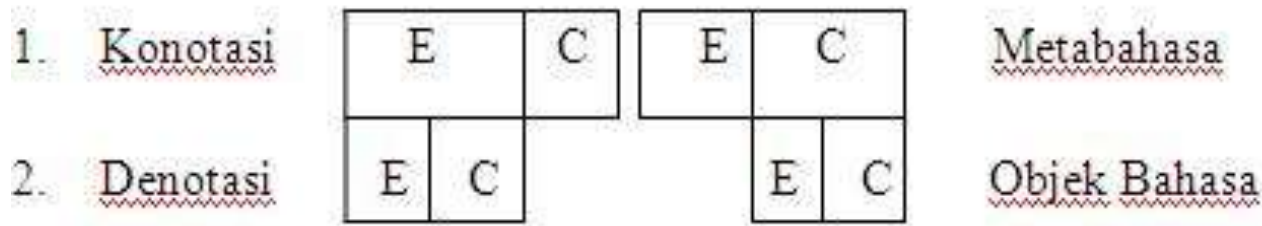

Gambar 1. Dua Sudut Artikulasi Barthes

Sumber : Barthes 1983, dikutip Kurniawan 2001

Bhinneka Tunggal Ika adalah moto atau semboyan bangsa Indonesia yang tertulis pada lambang negara Indonesia, Garuda Panca Sila. Frasa ini berasal dari bahasa jawa kuno yang artinya adalah "Berbeda-beda tetapi tetap satu". Jika diterjemahkan per kata, kata bhinneka berarti "beraneka ragam" atau berbeda-beda. Kata neka dalam bahasa Sanskerta berarti "macam" dan menjadi pembentuk kata "aneka" dalam Bahasa Indonesia. Kata tunggal berarti "satu". Kata $i k a$ berarti "itu". Secara harfiah Bhinneka Tunggal Ika diterjemahkan "Beraneka Satu Itu", yang bermakna meskipun berbeda-beda tetapi pada hakikatnya bangsa Indonesia tetap adalah satu kesatuan. Semboyan ini digunakan untuk 
menggambarkan persatuan dan kesatuan Bangsa dan Negara Kesatuan Republik Indonesia yang terdiri atas beraneka ragam budaya, bahasa daerah, ras, suku bangsa, agama dan kepercayaan.

(www.id.wikipedia.org/wiki/Bhinneka_Tunggal_Ika diakses pada 17 September 2017).

Bukalapak adalah website e-commerce yang berdiri sejak tahun 2009 yang didirikan oleh dua orang anak muda bernama Achmad Zaky dan Nugroho Herucahyono. Ter-ilhami dari kehidupan konsumtif masyarakat Indonesia yang aktif bermain di sosial media, serta pelaku usaha mikro, kecil, dan menengah yang saat itu belum melek pemasaran, manajemen, dan teknologi. Atas kondisi tersebut dan dengan tekad menciptakan sesuatu yang bermanfaat bagi banyak orang. akhirnya dibangunlah start up dengan nama Bukalapak.com, Dalam lima tahun kenaikannya mencapai 100 kali lipat dengan total anggota mencapai 500.000 UMKM dari seluruh Indonesia. (Avit Hidayat, 2015).

Bukalapak juga memiliki akun pada chanel youtube yang berisi bermacam iklan yang dibuat untuk memperkenalkan web commerce dan selalu di update sesuai tema dan kondisi keseharian. Untuk iklan yang diteliti penulis mengusung tema perayaan tahun baru Imlek pada tanggal 27 Januari 2017.

\section{STUDI LITERATUR}

Penelitian ini dilakukan merujuk pada penelitian yang menganalisis iklan berdasarkan pesan yang dihasilkan pada iklan, diambil dua penelitian sejenis.

Berdasarkan penelitian yang dilakukan Gisca Gaprita Sari (2013) melalui penelitiannya yang berjudul ANALISIS TANDA VERBAL IKLAN SMARTPHONE NTT DOCOMO DI MEDIA TELEVISI JEPANG : KAJIAN SEMIOTIK. Penelitian tersebut menggunakan teori semiotika Pierce, yang menghasilkan bahwa iklan tersebut memiliki karakteristik dimana muncul interpretasi berupa rasa khawatir yang dirasakan oleh anggota keluarga pemilik smartphone, yang diikuti dengan interpretasi bahwa smartphone NTT docomo berkualitas, praktis, dan bisa menjaga pemiliknya dalam kesusahan. Perwujudan smartphone NTT docomo sebagai manusia pada iklan ini digunakan untuk membangun rasa kepercayaan serta menjalin hubungan dekat antara smartphone NTT docomo dengan pemiliknya.

Penelitian berikutnya yang menganalisis media iklan adalah Sri Wahyuningsih (2014) melalui penelitian yang berjudul KEARIFAN BUDAYA LOKAL MADURA SEBAGAI MEDIA PERSUASIF

(Analisis Semiotika Komunikasi Roland Barthes dalam Iklan Samsung Galaxy Versi Gading dan Giselle di Pulau Madura). Penelitian tersebut menghasilkan representasi kearifan budaya lokal Madura. Kearifan lokal budaya Madura yang memiliki daya persuasif tersendiri. Pilihan tema budaya Madura oleh produser iklan sangat menarik dan mempunyai karakter tersendiri terutama tentang karapan sapi, pakaian adat Madura, serta bahasa maupun logat Madura. Pulau Madura yang berada di wilayah pulau Jawa Timur dikenal sebagai pulau garam, dan eksotik, sehingga dikenal secara nasional maupun internasional. Hasil dari analisis iklan hand phone di tersebut ditemukan beberapa konotasi: (1) adanya bentuk syukur masyarakat Madura dalam lensa, dan (2) karapan sapi, pakaian adat Madura, Bahasa Madura merupakan kearifan lokal budaya Madura.

Kesimpulan yang dapat peneliti ambil dari hasil kedua penelitian tersebut adalah pesan moral yang disajikan kepada penonton berupa: (1) rasa kasih sayang keluarga (2) kearifan lokal budaya Indonesia

\section{PEMBAHASAN}

Iklan dibuat untuk mempersuasi khalayak untuk memperhatikan pesan yang disampaikan tentang identitas pribadi perusahaan, biasanya dengan menggunakan slogan 
untuk membuat pembedaan karakteristik serta melalui pemberian pesan dan tampilan iklan yang menarik perhatian masyarakat.

Pada penelitian ini penulis menampilkan beberapa scene yang merepresentasikan nilainilai kebhinekaan yang dipisahkan berdasarkan makna konotatif dan denotatif dari iklan tersebut. Latar belakang iklan adalah kehidupan dua pemuda dari 2 suku dan agama yang berbeda, mereka datang ke kota Bandung untuk melanjutkan studi disalah satu perguruan tinggi yang ada disana, dan yang menginap di rumah seorang ibu paruh baya dari etnis tionghoa dengan menyewa kamar. Dari sini awal kisah kehidupan sehari-hari yang terjalin, kehidupan tanpa adanya batasan perbedaan pandangan Suku, Agama dan Ras. Diakhiri dengan kalimat "Keluarga tak harus pertalian darah, tapi juga pertalian hati".

Tabel 1. Artikulasi Rolan Barthes

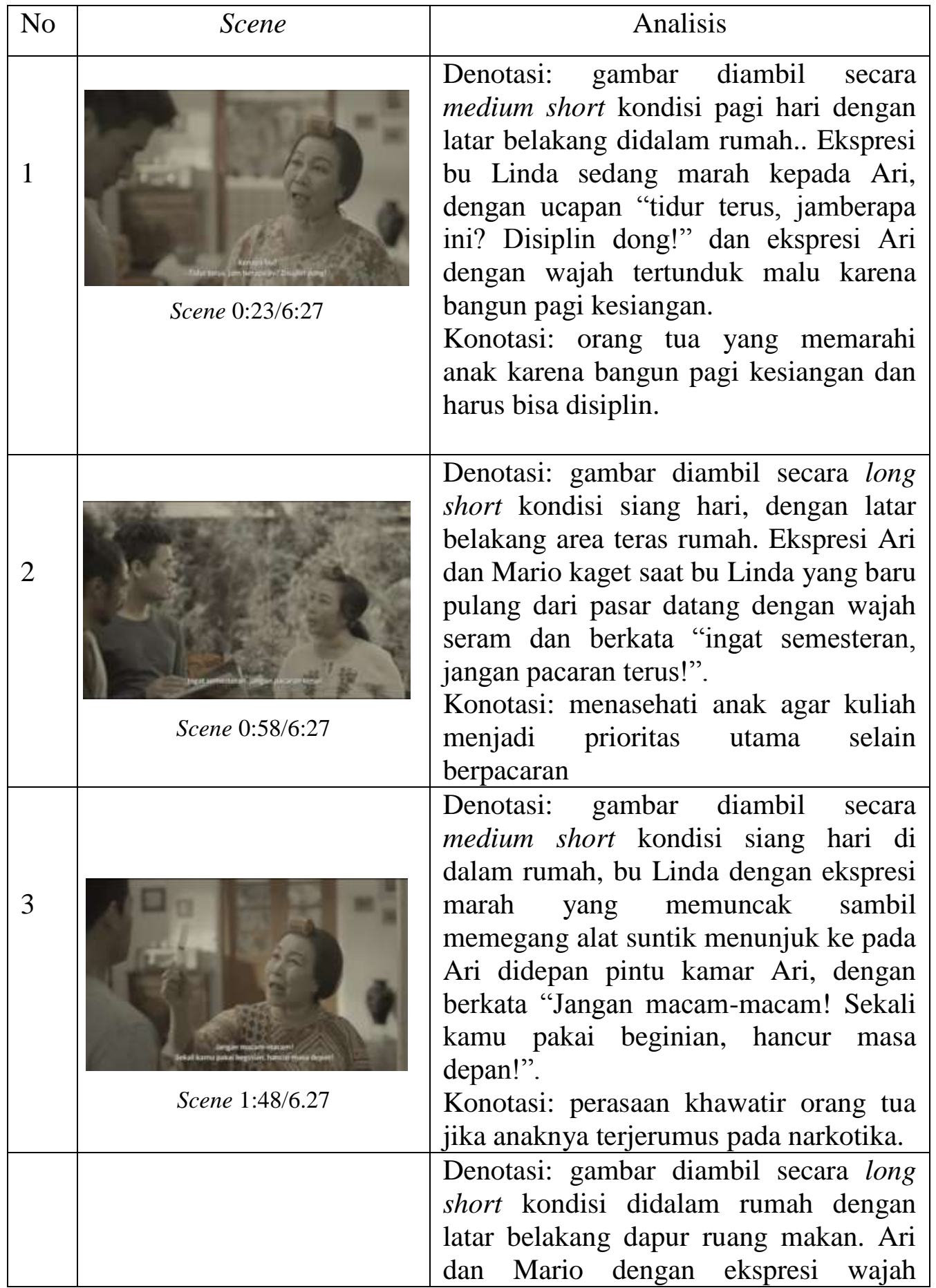




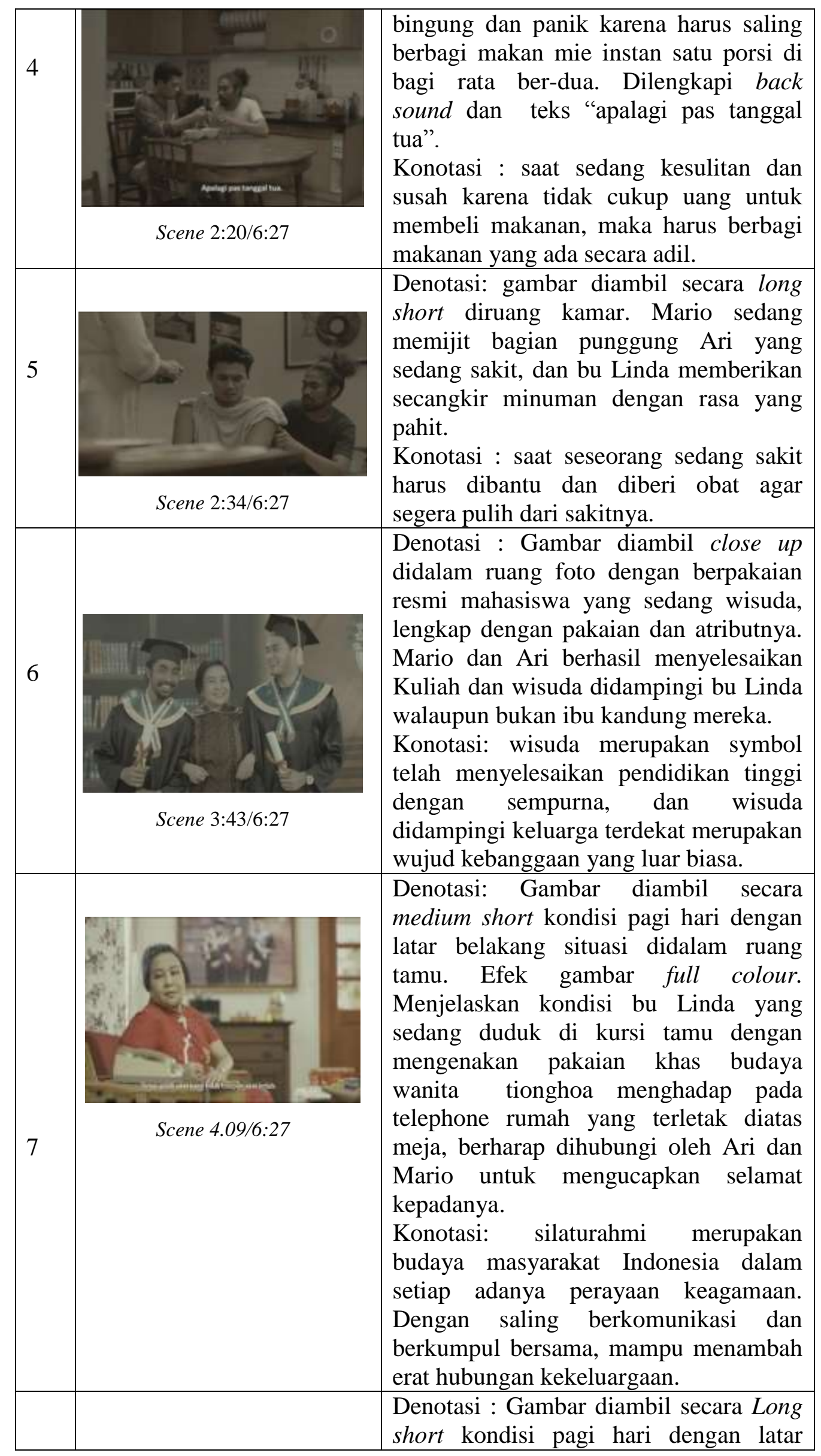




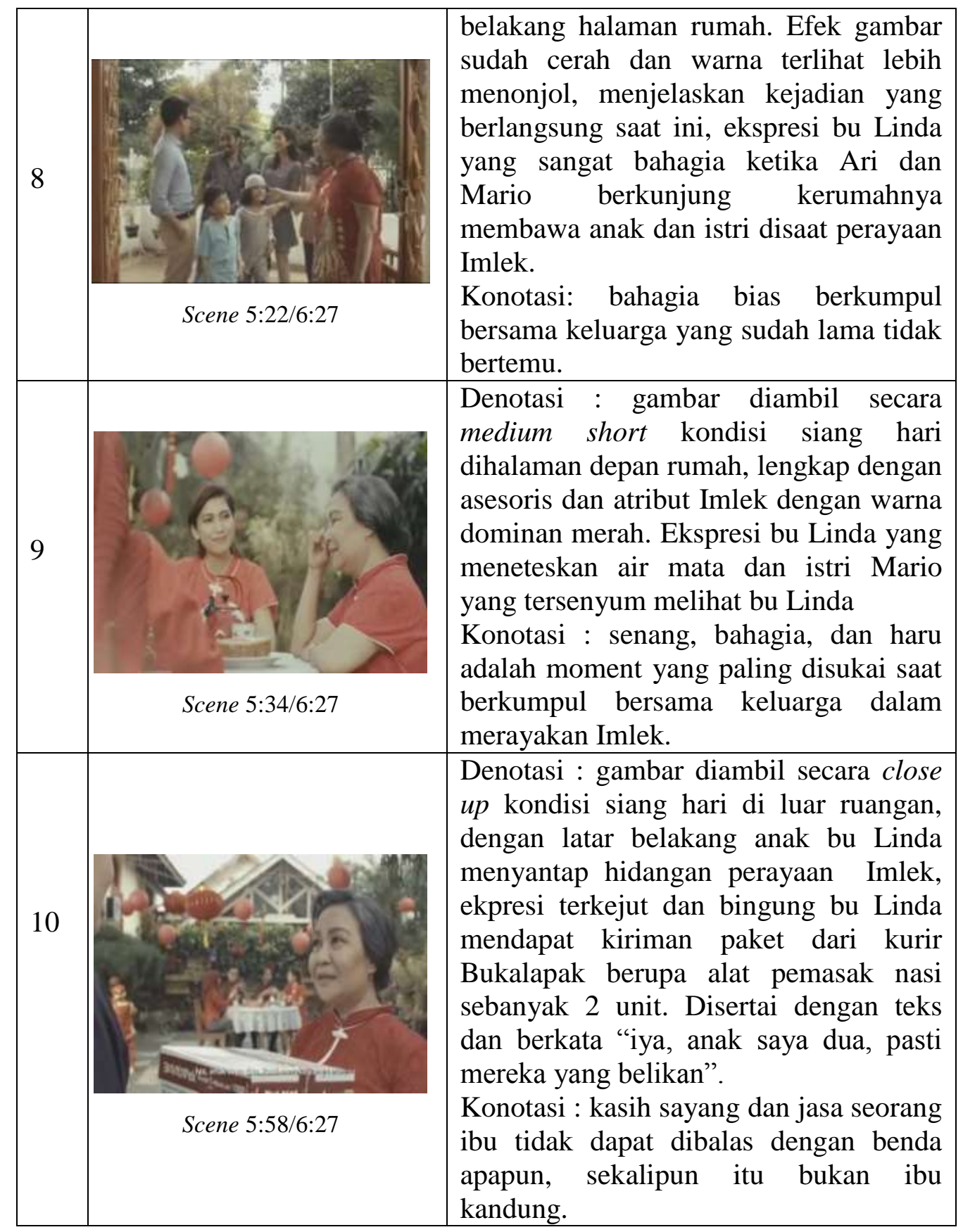

\section{Pertalian Antara Ibu Dan Anak}

Dalam iklan ini tergambar beberapa scene yang menonjolkan karakter sorang ibu yang sangat peduli kepada anaknya sekalipun bukan anak kandung yang juga tidak dikenal betul siapa orang tua kandungnya. Bahkan mereka sebelumnya tidak saling kenal.

Pada gambar 1, pada scene 0.23 tampak pemeran bu linda dengan penampilan masih mengenakan pakaian tidur dan rambut digulung keatas dengan pengait rambut, sedang marah kepada Ari yang selalu terlambat bangun pagi, dan bu Linda menasehati agar menerapkan kedisiplinan didalam dirinya. Gambar 2, pada Scene 0:58, menggambarkan dimana Ari dan Mario baru saja kedatangan teman wanita yang mengembalikan buku di tempat tinggal Ari, dan bu Linda yang baru pulang belanja dari pasar menyaksikan hal tersebut dan menasehati Ari dan Mario agar lebih mengutamakan pendidikan daripada berpacaran. Gambar 3. Pada Scene 1:48, tampak ekspresi bu Linda yang kecewa, dengan 
raut wajah seram dan bernada marah kepada Ari sambil mengacungkan alat suntik yang ia temukan ditempat sampah didepan pintu kamar Ari, memarahi Ari karena khawatir Ari menggunakan narkotika, sedangkan Ari terdiam menyaksikan kemarahan bu Linda.

Dapat disimpulkan kisah cerita bagaimana seorang ibu yang selalu menasehati anakanaknya demi kebaikan. Peran bu Linda sebagai tokoh ibu yang selalu peduli dan perhatian kepada Ari dan Mario yang sudah dianggap seperti anak sendiri, dengan tidak pernah bosan untuk selalu marah dan menasehati jika anaknya melakukan kesalahan.

Adalah rasa kasih dan sayang seorang ibu kepada anaknya yang khawatir jika anaknya menjadi anak yang tidak berguna dan gagal dalam menempuh pendidikan demi menggapai masa depan, hal tersebut digambarkan pada adegan dimana bu Linda menasehati Ari agar berlaku hidup displin terhadap waktu karena terlambat bangun pagi, hal lain juga tergambar pada saat Mario dan Ari baru mendapatkan kembali buku yang baru dipulangkan oleh dua orang wanita cantik adik kelas mereka dan terlihat oleh bu Linda yang baru pulang dari pasar, kemudian menasehati kembali mereka agar jangan berfikir untuk berpacaran, tetapi harus fokus pada perkuliahan. Hal lain juga tergambar dari ekspresi wajah panik dan kemarahan besar ketika bu Linda melihat alat suntik didalam tempat sampah didepan pintu kamar Ari dan marah-marah kepada Ari meminta penjelasan dari temuan alat tersebut, ini menunjukkan rasa takut seorang ibu jika anaknya sampai terjerumus dengan Narkotika dan obat-obat terlarang yang dapat merusak masa depan.

Sikap disiplin merupakan dasar dari karakter manusia, jika seseorang menerapkan kedisiplinan terutama dalam kesehariannya, dipercaya akan menjadi orang yang sukses, seperti halnya tokoh-tokoh sukses dan terkenal yang sejak awal untuk menggapai kesuksesan diawali pola hidup disiplin, terutama disiplin waktu.

\section{Sahabat Adalah Saudara}

Iklan ini menggambarkan keakraban dan kekompakan teman seperti layaknya saudara dekat.

Pada gambar 4, pada Scene 2:20 menggambarkan kondisi dimana Ari dan Mario sedang duduk bersama di meja makan dengan latar belakang ruang dapur sedang menikmati makan malam, mereka saling berbagi mie instan yang berisi satu porsi harus dibagi menjadi 2 (dua) mangkuk untuk mereka makan, selanjutnya bu Linda datang menghampiri mereka dengan membawa penanak nasi dan memberikan kepada mereka untuk dapat dimakan bersama. Gambar 5, pada Scene 2:34 tampak Ari dan Mario sedang berada didalam ruang kamar sedang duduk diatas kasur dengan kondisi Ari membelakangi Mario yang sedang menolong Ari yang sedang masuk angin, kemudian bu Linda datang menghampiri mereka dikamar sambil membawakan obat untuk diminum Ari agar sakitnya lekas sembuh. dan gambar 6 pada Scene 3:43 tampak Ari dan Mario dengan mengenakan pakaian toga dan bu Linda berada diantara mereka, dengan raut wajah senang dan senyum bahagia dari Ari dan Mario sudah dapat menyelesaikan studi mereka dan memiliki tokoh ibu yang mendampingi mereka disaat wisuda.

Dari ketiga scene tersebut dapat disimpulkan bagaimana persahabatan yang saling tolong menolong dalam senang maupun susah.

Dalam gambar terlihat Ari dan Mario tidak segan untuk saling berbagi makanan mie instan yang hanya satu porsi harus dibagi bersama sekalipun dalam kondisi kelaparan karena mereka masih menunggu uang kiriman dari orang tua mereka. Adapula saat dimana Ari sedang sakit, Mario tanpa ragu membantu mengurut badan Ari dan bu Linda yang dengan sigap membuatkan obat dan memberikannya kepada Ari untuk segera diminum agar segera sembuh. Hal ini menggambarkan sikap mereka yang bersama dalam keadaan susah. Terlihat pula kondisi dimana Ari dan Mario berfoto wisuda didampingi bu Linda yang sudah menggantikan peran ibu mereka saat acara wisuda 
Disini tergambar bahwa untuk membantu yang sedang kesulitan tidak harus memandang saudara atau bahkan suku dan agama yang sama. Bahkan kebahagiaan saat pelaksanaan wisuda dapat didampingi bu Linda sekalipun itu bukan ibu kandung mereka.

\section{Perbedaan Keyakinan Tetap Bersaudara}

Dalam iklan ini juga menceritakan bagaimana perbedaan agama tidak lantas menjadi pembatas dalam hubungan kekeluargaan.

Pada gambar 7 scene 4.09 tampak kondisi bu Linda dengan raut wajah sedih dengan mengenakan pakaian khas kaum wanita tionghoa berwarna merah cerah, sedang duduk di kursi ruang tamu, sambil memandangi telepon rumah yang tidak berdering, menantikan Ari dan Mario menghubunginya saat perayaan imlek.

Gambar 8 pada Scene 5:22 tampak kondisi orang sedang berkumpul didepan teras rumah, yang menceritakan kehidupan setelah beberapa waktu kedepan sejak Ari dan Mario lulus kuliah. menceritakan bagimana kehidupan Ari dan Mario setelah menyelesaikan kuliah dan sudah mapan bersama anak dan istri masing-masing, dan kembali bersilaturahmi dirumah bu Linda tempat mereka menyewa kamar semasa kuliah untuk merayakan tahun baru Imlek bersama.

Gambar 9 pada scene 5.34, menceritakan kondisi keluarga Ari, Mario bersama bu Linda sedang duduk bersama di meja makan yang diletakkan diluar rumah sambil menikmati hidangan imlek yang sudah disediakan oleh bu Linda. Pada scene ini bu Linda terlihat sedang sedih bahagia sampai meneteskan air mata menyaksikan kerukunan dan kebahagiaan saat berkumpul bersama tanpa adanya batasan keyakinan dan perbedaan budaya. dan gambar 10 pada scene 5.58, menceritakan bu Linda didatangi oleh 2 orang kurir membawakan paket kiriman yang diberikan kepadanya. Bu Linda merasa bahagia ternyata pekat tersebut berisi alat penanak nasi yang dikirimkan oleh Ari dan Mario untuk dapat digunakan olehnya.

Tergambar karakter Ari dan istrinya sebagai seorang muslim dengan menggunakan mukena pada kepalanya, yang saat menghampiri rumah bu Linda mengucapkan kata salam "assalamua'laikum". Dan disambut oleh bu Linda dengan "wa'alaikumsallam". Kemudian Ari dan keluarga dan Mario beserta anak istrinya mengucapkan "gong xi fat Chai nek". Selanjutnya mereka berkumpul bersama dalam merayaan Imlek, sebagai bentuk penghormatan kepada bu Linda, keluarga Ari dan Mario turut mengenakan busana bernuansa Merah yang melambangkan etnis Tionghoa, dan membaur menjadi satu dalam kebahagiaan bersama.

Dalam agama islam diwajibkan untuk mengucakan dan menjawab salam, salam merupakan ungkapan doa sekaligus persahabatan dan persaudaraan (ukhuwah). Karena doa itu merupakan ibadah, maka mengucapkan salam (dan menjawabnya) merupakan ibadah.

kalimat "Gong Xi Fa Chai" memiliki arti Selamat Sejahtera. Pemberian nama "Gong Xi $\mathrm{FaChai"} \mathrm{berawal} \mathrm{dari} \mathrm{kata} \mathrm{"Gong} \mathrm{Xi"} \mathrm{yang} \mathrm{memiliki} \mathrm{arti} \mathrm{selamat} \mathrm{karena} \mathrm{penduduk}$ Tiongkok pada zaman dahulu selamat dari binatang buas. Lalu kata "Fa Chai" memiliki sejarah dari sebuah kesejahteraan yang seiring perkembangan zaman semakin baik di tengah masyarakat Tionghoa.

\section{KESIMPULAN}

Penelitian ini membuktikan bahwa, iklan yang buat oleh toko online Bukalapak dengan tema "Bu Linda" ditayangkan melalui chanel youtube yang di publish pada 26 Januari 2017 bertepatan dengan perayaan Imlek ini mampu memberikan banyak makna yang mendalam bagi setiap penontonnya, khususnya makna Bhineka Tunggal Ika yang menjadi dasar Negara Indonesia yang berarti Berbeda-beda tetapi tetap satu. Hal ini terbukti dengan jumlah viewer yang mencapai 1,6 juta kali tonton, mendapat lebih dari 29 
ribu like oleh penonton dan lebih dari 2 ribu komentar dari nettizen yang memuji iklan ini dengan sarat makna yang ada didalamnya.

Iklan yang dibuat dalam rangka memperingati imlek tahun 2017 ini menceritakan karakter Ari yang berlatar belakang suku jawa dan beragama Islam, Mario dari suku Ambon yang berlatar belakang agama Kristen, dan bu Linda dari etnis keturunan Tionghoa beragama Budha. Mereka hidup dalam satu rumah dengan kehidupan dan kepribadian masing-masing dan tidak ada terjadi konflik antar perbedaan pandangan, paling menonjol adalah karakter bu Linda yang berperan sebagai seorang ibu yang sangat menyayangi mereka sebagai anak-anaknya, dengan perhatian dan tidak bosan untuk selalu menasehati Ari dan Mario dalam setiap kesempatan agar menjadi anak yang suskses meraih masa depan. Bahkan karakter bu Linda dalam iklan tersebut mencerminkan kasih sayang seorang ibu kepada anak kandungnya yang rela menolong disaat Ari dan Mario sedang menghadapi masalah, dan merasa terharu saat Ari dan Mario membawa serta anak dan istri mereka untuk mengunjungi bu Linda saat perayaan hari besar Imlek dan merayakan bersama-sama dengan penuh suka cita.

Iklan ini dibuat untuk menunjukkan kepada penonton, bahwa rasa persaudaraan itu tidak hanya terlihat dari satu suku, agama, maupun etnis, tetapi juga bisa bercampur, dan saling hormat-menghormati antar sesama adalah wujud dasar Negara Indonesia yang tercermin pada kalimat "Bhineka Tunggal Ika" yang berarti walau berbeda tetapi tetap satu.

\section{DAFTAR PUSTAKA}

[1] Arikunto, Suharsimi. 1998. Prosedur Penelitian Suatu Pendekatan Praktek. Jakarta: PT Rineka Cipta.

[2] Budiman, Manneke. 2001. "Semiotika dalam Tafsir Sastra: Antara Riffaterre dan Barthes"dalam Bahan Pelatihan Semitika. Jakarta: Pusat Penelitian Kemasyarakatan dan Budaya LPUI.

[3] Bogdan, Peter dan Steven, J. Taylor. 1992. Introduction to Qualitative Researh Methods: A Phenomenological Approach in The Social Science. Arif Furchan, penerjemah. Surabaya: Usaha Nasional.

[4] Frank F. Jefkins. 1982. Introduction to Marketing, Advertising, and Public Relation. London: Macmillan Press Ltd.

[5] Hoedoro, Benny. 2014. Semiotik dan dinamika Sosial Budaya. Edisi ketiga, Depok: Komunitas Bambu.

[6] Kurniawan. 2001. Semiologi Roland Barthes. Magelang: Yayasan Indonesiatera.

[7] Nazir, Moh. 2005. Metode Penelitian. Ciawi: Ghalia Indonesia.

[8] Noviani, Ratna. 2002. Jalan Tengah Memahami Iklan, Yogyakarta: Pustaka Pelajar.

[9] Piliang, Yasraf Amir. 2003. HIPERSEMIOTIKA : Tafsir Cultural Studies Atas Matinya Makna, pengantar : bambang Sugiharto. Yogyakarta: Jalasutra.

[10] Sobur, Alex. 2003. Semiotika Komunikasi. Cetakan ketiga. Bandung: PT. Remaja Rosdakarya

[11] Wahyuningsih, Sri. 2013. Desain Komunikasi Visual, Bangkalan, UTM Press. 
[12] Gaprita, Giska. 2014. Analisis Tanda Verbal Iklan Smartphone NTT DOCOMO di Media Televisi Jepang: Kajian Semiotik

[13] Wahyuningsih, Sri. 2014. KEarifan Budaya Lokal Madura Sebagai Media Persuasif (Analisis Semiotika Komunikasi Roland Barthes dalam Iklan Samsung Galaxy Versi Gading dan Giselle di Pulau Madura)

[14] Representasi Budaya Indonesia pada Iklan Kopi Kapal Api Versi "Secangkir Semangat Untuk Indonesia” di Televisi Swasta).

\section{Online:}

[15]

Avit

Hidayat,

juni

2015

https://www.tekno.tempo.co/read/news/2015/06/02/072671421/begini-kisah-zaky-

membangun-bukalapak-com diakses pada 12 Agustus 2017.

[16] www.id.wikipedia.org/wiki/Bhinneka_Tunggal_Ika diakses pada 17 September 2017. 